\title{
COMPARISONS OF UNIFORM AND VARIABLE RATE NITROGEN FERTILIZER APPLICATIONS IN REAL CONDITIONS - EVALUATION OF POTENTIAL IMPACT ON THE YIELD OF WHEAT AVAILABLE FOR USE IN ANIMAL FEED
}

\author{
Jakub Elbl ${ }^{1}$, Jiří Mezera ${ }^{1}$, Antonín Kintl², Petr Širůček¹, Vojtěch Lukas ${ }^{1}$ \\ ${ }^{1}$ Department of Agrosystems and Bioclimatology, Faculty of AgriSciences, Mendel University in Brno, \\ Zemědělská 1, 61300 Brno, Czech Republic \\ ${ }^{2}$ Agricultural Research, Ltd., Zahradní 1, 66441 Troubsko, Czech Republic
}

Link to this article: https://doi.org/10.11118/actaun.2021.003

Received: 16. 6. 2020, Accepted: 14. 12. 2020

To cite this article: ELBL JAKUB, MEZERA JIŘÍ, KINTL ANTONÍN, ŠIRU゚ČEK PETR, LUKAS VOJTĚCH. 2021. Comparisons of Uniform and Variable Rate Nitrogen Fertilizer Applications in Real Conditions - Evaluation of Potential Impact on the Yield of Wheat Available for Use in Animal Feed. Acta Universitatis Agriculturae et Silviculturae Mendelianae Brunensis, 69(1): 33-43.

\begin{abstract}
The presented research deals with the variable application of $\mathrm{N}$ fertilizers (VRA NF) in the stand of winter wheat and with possibilities for evaluating the effect of such application on grain yield. The effect of VRA NF was assessed in close cooperation between Spearhead Czech Ltd. and Mendel University in Brno within an operational experiment. In 2018 and 2019, three experimental plots were always chosen on which VRA NF was implemented by conventional technique according to application maps. Each application map included control strips with the uniform NF application. The application maps were prepared based on the spectral analysis of satellite images. The individual plots were divided into three zones: Zone 1 with the lowest yield potential, Zone 2 with the medium yield potential, Zone 3 with the highest yield potential. The highest dose of $\mathrm{N}$ was at all times applied in Zone 3, and conversely the lowest dose was applied in Zone 1. In 2018 and 2019, the experimental fields were harvested by harvester New Holland CX 8080 which was equipped with the technology for the monitoring of grain yields. The main goal of data processing was to remove error data at first and then to re-calibrate them using the information about the weight of harvested grain. The expected benefit, i.e. a yield increase by min. 3\% was found only in 2018, when the benefit was about $5 \%$. In the following year, the difference between the conventional application of $\mathrm{N}$ and VRA technologies was minimal. However, this condition was probably caused by drought which negatively affected all stands. In particular, measured values of grain yield do not indicate the negative effect of VRA NF on grain yield. This research further showed the applicability of yield data acquired by harvest technology; however, the elimination of error data is necessary as well as their re-calibration according to total yield ascertained by weighing the total production of grain from a specific plot.
\end{abstract}

Keywords: variable rate application, nitrogen, winter wheat, Sentinel, Spot, NDVI

\section{INTRODUCTION}

Precision agriculture is a method of farming on agricultural land that takes into account the variability of land and adapts production inputs to environmental conditions. The system is supported by modern technologies including the global 
positioning system (GPS), geographic information systems (GIS), remote sensing, sensors and more (Santhosh et al., 2003). The main aim of precision agriculture is to use material inputs, such as mineral fertilizers, pesticides and fuels more efficiently by appropriate management based on local plant requirements and the state of soil environment (Mulla, 2012).

One of basic factors in generating crop yields is nitrogen fertilization. Achieving expected yields and reducing the burden on the environment by nitrogen losses at the same time is possible only with the correct use of nitrogen fertilizers, especially in the condition of higher spatial variability of agricultural fields (Handlírová et al., 2007; Hlavinka et al., 2013; Sutton, 2011; Lošák et al., 2014). A possible solution could be using a variable rate application (VRA) of nitrogen fertilizers. The aim of fertilizer variable rate application is to optimize the input of nutrients into the soil so that the applied amount is largely utilized by plants according to management zones representing areas with homogeneous soil conditions and to address site-specific changes in soil properties as well as the nutritional status of plants with the consequent higher efficiency of nitrogen utilization by plants and lower risk of nitrogen leakage into the environment (Shanahan et al., 2008; Diacono et al., 2013; Sutton, 2011). According to Sutton (2011), mineral fertilizers represent the main source of the contamination of underground sources of drinking water with $\mathrm{N}$ substances. Plants mostly use about $42-47 \%$ of applied N (Zhang et al., 2015). The rest of it is irretrievably lost by washout, volatilization or in the form of $\mathrm{NO}_{\mathrm{x}}$ oxides (Sutton, 2011; Li et al., 2016; Lal et al., 2018). The application of $\mathrm{N}$ fertilizers with the emphasis on taking into account the nutritional requirements of plants and yield potential of the site leads to better utilization of nitrogen by plants, to reduced doses of $\mathrm{N}$ fertilizers and to the reduced risk of $\mathrm{N}$ loss from the soil while maintaining profitable yield of the grown crop (Li et al., 2016). Nowadays, the VRA of nitrogen topdressing is based on the remote sensing of the crop by satellites, aerial or unmanned surveys, or by on-the-go proximal sensing.

The review by Diacono et al. (2013) provides a summary of tools and approaches for site specific nitrogen management, which includes techniques for plant diagnosis by proximal and remote sensing, estimation of nitrogen use efficiency and profitability of variable nitrogen application. In most of cases, spectral measurement of crop stands is utilized to estimate the crop $\mathrm{N}$ status by calculation of vegetation indices derived from the proximal on-the-go (Heege et al., 2008) or remote sensing systems (Hansen and Schjoerring, 2003). Based on the knowledge (Shanahan et al., 2008; Diacono et al., 2013; Heege et al., 2008), the remote technology with the highest performance is the most accessible tool for the variable rate application of $\mathrm{N}$ in order to obtain data for the assessment of field crops. The Sentinel 2, Landsat 8 or Spot 6 satellites routinely deliver optical images of the Earth and use band configuration in red-edge and near infrared region, which is necessary for high sensitivity to detect the chlorophyll content in plants (Delegido et al., 2011). The knowledge of chlorophyll content is a necessary assumption for preparing the information background (i.e. prescription or application maps) reflecting the actual situation of plants on the plot. The background is used for targeted $\mathrm{N}$ application based on the maps.

One of other methods for the assessment of site variability or $\mathrm{N}$ fertilization effectiveness is the mapping of crop yields. The crop yields are scanned by means of grain yield sensors that are parts of modern combine harvesters. Results of sensor data processing are yield maps describing the distribution of yields from partial plots of the site as a reflection of soil fertility of the given partial plot. Thus, the yield maps reflect spatial yield trends on the given plots, which include all influences affecting the harvested crop during vegetation. Useful is to compare yields in individual years, which subsequently allows classification of the plots into classes (zones) according to yield level and degree of stability (Blackmore et al., 2003).

The main goal of the presented study was to determine the effect of variable rate application of $N$ fertilizers (VRA NF) on the grain yield of winter wheat. The secondary objectives were:

a) to assess the procedure of yield data processing,

b) to test a possible use of control strips with the uniform application in the prescription maps for VRA $\mathrm{N}$ fertilizers as a tool for checking VRA $\mathrm{N}$ efficiency.

\section{MATERIALS AND METHODS}

\section{Field Experiment Organization}

The effect of the selected VRA technology was tested at Eurofarms Jihlava (EF J) from 2017 (Fig. 1). EF J Ltd. is a part of Spearhead Czech Ltd. (SIL CZ) and technologies for variable fertilizer application have been used there since 2012. The above-mentioned objectives were tested in a field experiment (> $250 \mathrm{ha}$ ) on plots seeded with winter wheat every year. The presented data about the potential effect of VRA of $\mathrm{N}$ were obtained during the last two vegetation seasons from three fields with winter wheat (varieties Lear in 2018 and Sheriff in 2019) in both years. Characteristics of the varieties were as follows:

A) Lear represents a late wheat variety intended for feed purposes, but also suitable for the production of wafers and malt. It has a medium to high rooting capacity and is suitable for cultivation in all production regions of Czech Republic. 


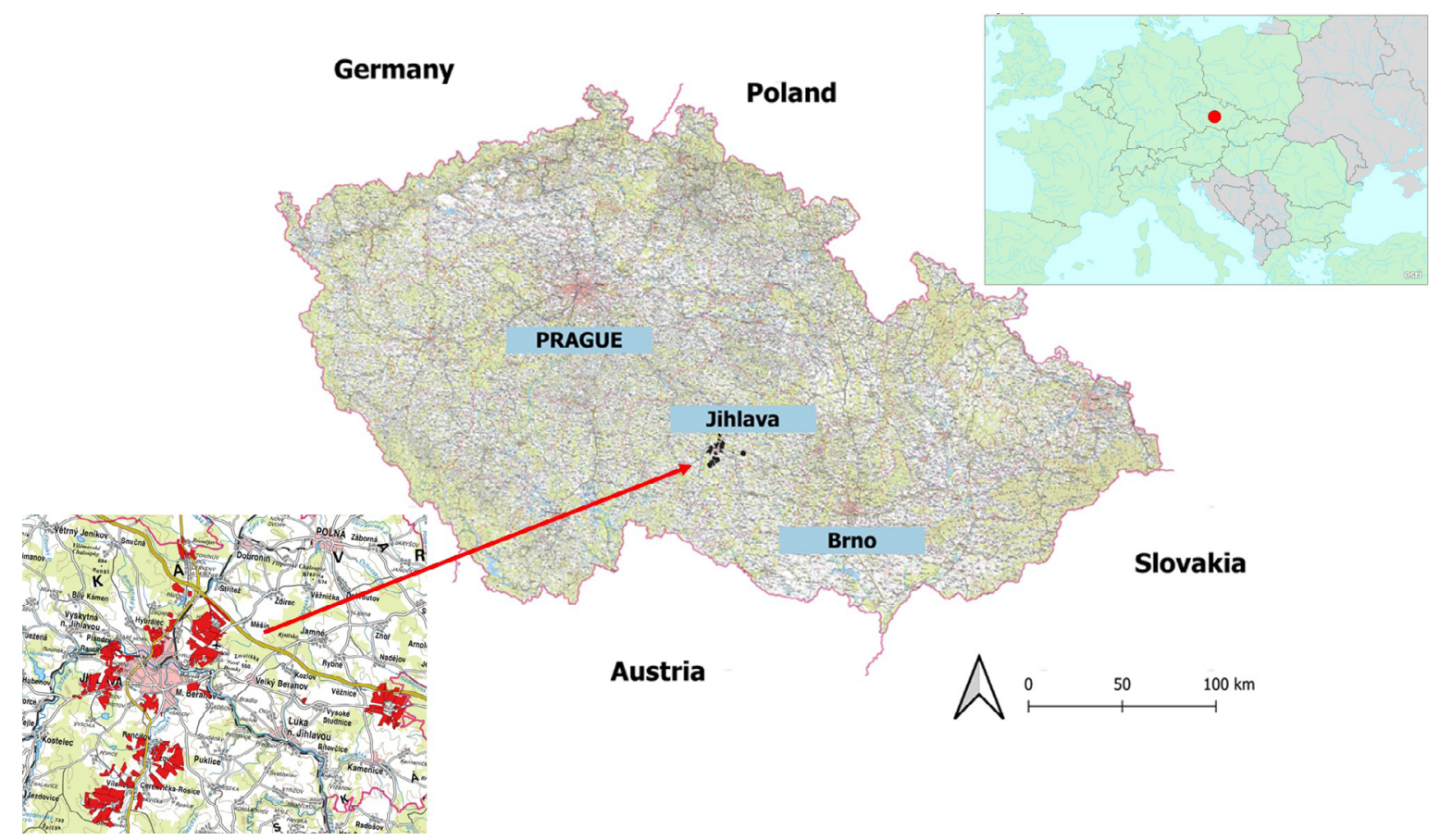

1: Localization of experimental fields WMS map data source: CUZK

I: Meteorological and climatological parameters of the studied area

\begin{tabular}{lccccc}
\hline Year & $\begin{array}{c}\text { Mean annual } \\
\text { precipitation }(\mathrm{mm})\end{array}$ & $\begin{array}{c}\text { Mean annual } \\
\text { temperature }\left({ }^{\circ} \mathrm{C}\right)\end{array}$ & Time period & $\begin{array}{c}\text { Precipitation per } \\
\text { period }(\mathrm{mm})\end{array}$ & $\begin{array}{c}\text { Mean temperature } \\
\text { per period }\left({ }^{\circ} \mathrm{C}\right)\end{array}$ \\
\hline 2018 & 567 & 9.28 & IV-VI & 221 & 15.3 \\
2019 & 458 & 9.37 & IV-VI & 135 & 13.5 \\
Long term standard & 644 & 7.2 & IV-VI & 329 & 11.4 \\
\hline
\end{tabular}

Comments: Parameters for 2018 and 2019 were measured by DAVIS Vantage Pro2 meteorological station (Davis Instruments, California, USA). The station is located in Jihlava-Heroltice (538 $\mathrm{m}$ a.s.l.) and operated by EF J. Data for the long-term standard (1961-1990) are for the Vysočina Region and were prepared based on data available from the Czech Hydrometeorological Institute (http://portal.chmi.cz/historicka-data/).

B) Sheriff can be defined as a non-bakery semilate variety suitable for feeding purposes. It is a plastic variety suitable for cultivation in all production regions of the country.

Both varieties are legally protected and bred by Limagrain UK Ltd. The two wheat varieties have similar properties and were grown to produce animal feed. The application of $\mathrm{N}$ fertilizers (NF) was divided into three doses: $\mathrm{N} 1=$ regeneration dose (BBCH 25-29: tillering), N2 = production dose (BBCH 30-35: stem elongation) and N3 = qualitative dose (BBCH > 37-39: flag leaf).

The total need for $\mathrm{N}$ nutrition $(\mathrm{kg} / \mathrm{ha})$ of winter wheat was determined annually on the basis of soil $\mathrm{N}_{\min }$ content and planned yield. The optimal dose of $\mathrm{N}_{\min }$ was calculated from Eq. 1 which was prepared according to Klem et al. (2011), Lukas et al. (2012) and Aranguren et al. (2019).

Dose of $N_{\min }(\mathrm{kg} / \mathrm{ha})=$

$=($ planned yield $\times 25)-N_{\min }$ stock in topsoil where:

- planned yield was determined on the basis of three-year average grain yield for the selected experimental plot.

- 25 represents the minimum amount of N (25 kg) needed to produce 1 tonne of grain and the corresponding straw production.

- $\mathrm{N}_{\min }$ stock in topsoil (kg N/ha) was calculated as a content of individual $\mathrm{N}_{\min }$ forms $(\mathrm{mg} / \mathrm{kg})$ in the soil $\times$ soil bulk density.

$\mathrm{N}$-fertilizers used in the experiment were as follows:

a) Urea Stabil for regeneration dose,

b) DAM 390 for production dose and LAD 27 for qualitative dose of $\mathrm{N}$.

All used fertilizers are registered under the Fertilizers Act No. 156/1998 Sb. for use in the Czech Republic or another EU Member Country. Urea Stabil (Witt Handel GmbH Hamburg, DEU) (1) is urea treated with the addition of NBPT urease inhibitor, which stabilizes urea, slows down its 


\begin{tabular}{|c|c|c|c|c|c|c|}
\hline \multirow{2}{*}{ Treatment } & \multirow{2}{*}{ Designation } & \multirow{2}{*}{ Characteristics } & \multicolumn{3}{|c|}{ Average dose of mineral $\mathrm{N}(\mathrm{kg} / \mathrm{ha})$} & \multirow[t]{2}{*}{$\begin{array}{c}\text { Total dose of mineral N } \\
(\mathrm{kg} / \mathrm{ha})\end{array}$} \\
\hline & & & N1 & N2 & N3 & \\
\hline Variable & Zone 1 & lowest yield potential & \multirow{4}{*}{46} & 54 & 36 & \multirow{4}{*}{155} \\
\hline Variable & Zone 2 & medium yield potential & & 66 & 43 & \\
\hline Variable & Zone 3 & highest yield potential & & 78 & 51 & \\
\hline Uniform & UNI & flat rate NF application & & 66 & 43 & \\
\hline
\end{tabular}

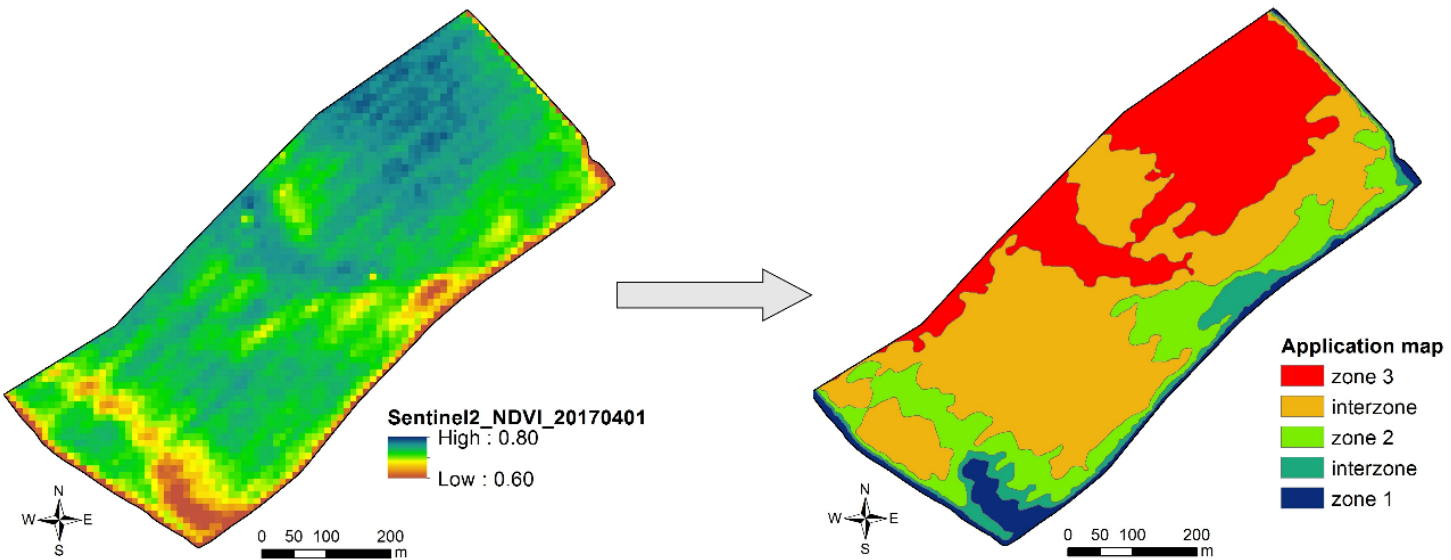

2: Example of NDVI based application map preparation (Elbl et al., 2018)

decomposition and reduces nitrogen losses through ammonia leakage after soil application. Above all, it contains 46\% of amide N. DAM 390 (Duslo, Ltd. Šala, SVK; registration no.: E43) is a solution of urea ammonium nitrate with an average nitrogen content of $30 \%$ by weight. The liquid fertilizer contains $39 \mathrm{~kg} \mathrm{~N}$ in $100 \mathrm{l}$ of solution and has $1300 \mathrm{~kg} / \mathrm{m}^{3}$ at $25^{\circ} \mathrm{C}$. LAD $27 \mathrm{~N}$ (Lovochemie Ltd., CZE; registration no.: E78) or ammonium nitrate is a fertilizer which contains nitrate and ammonium nitrogen $(27 \%)$ and $4.1 \%$ of magnesium.

The principle of fertilization (Fig. 2) was as follows: the selected plots with winter wheat were analysed on the basis of satellite images (Sentinel 2, SPOT) which were processed by SatAgro Ltd. with the use of spectral analysis. These images were taken approximately 5 and 10 days before the planned application of $\mathrm{N}$ fertilizer. The spectral behaviour of plants is characterized mainly by significantly increased reflectivity in the near infrared part of the spectrum. Radiation in the visible part of the spectrum is significantly absorbed, mainly by chlorophyll. The above analysis resulted in a multispectral map of NDVI vegetation index which expresses the relationship between reflectance in the interval of the red visible part of the spectrum and in the near infrared part of the spectrum. The multispectral map was then used for vegetation mapping - determination of yield potential (YP) of individual parts of the field. The YP corresponded to the stand density and to the potential chlorophyll content in the plants, which is sensitive to their condition. These data were subsequently used to prepare the application map of individual fields. The individual fields were divided into three zones: Zone 1 with the lowest yield potential, Zone 2 with the medium yield potential, Zone 3 with the highest yield potential. The surface area of each zone was at least 0.5 ha. VRA N was used only for N2 and N3 dose of $\mathrm{N}$, the highest/lowest dose of $\mathrm{N}$ being always applied to Zone 3 and Zone 1, respectively.

Each monitored plot contained a control strip (Figs. 3, 5) used to apply a flat rate of fertilizer thus representing the control. For the purpose of the presented study, only plots with the control strips were selected for the comparison of uniform and variable rate applications. This system of experiment organization allowed us to measure yield in all areas of the experimental field - without or with using the VRA technology. This variable application monitoring system was used for the first time in 2018 and is still being improved. The goal is that all application maps used contain these control strips and, after each harvest, the used VRA NF settings can be controlled.

\section{Yield Estimation}

In 2018 and 2019, the selected experimental fields were harvested with using the New Holland CX 8080 harvester equipped with the technology for monitoring the grain yield. Following the harvest, yield data from the above combine harvester for the 


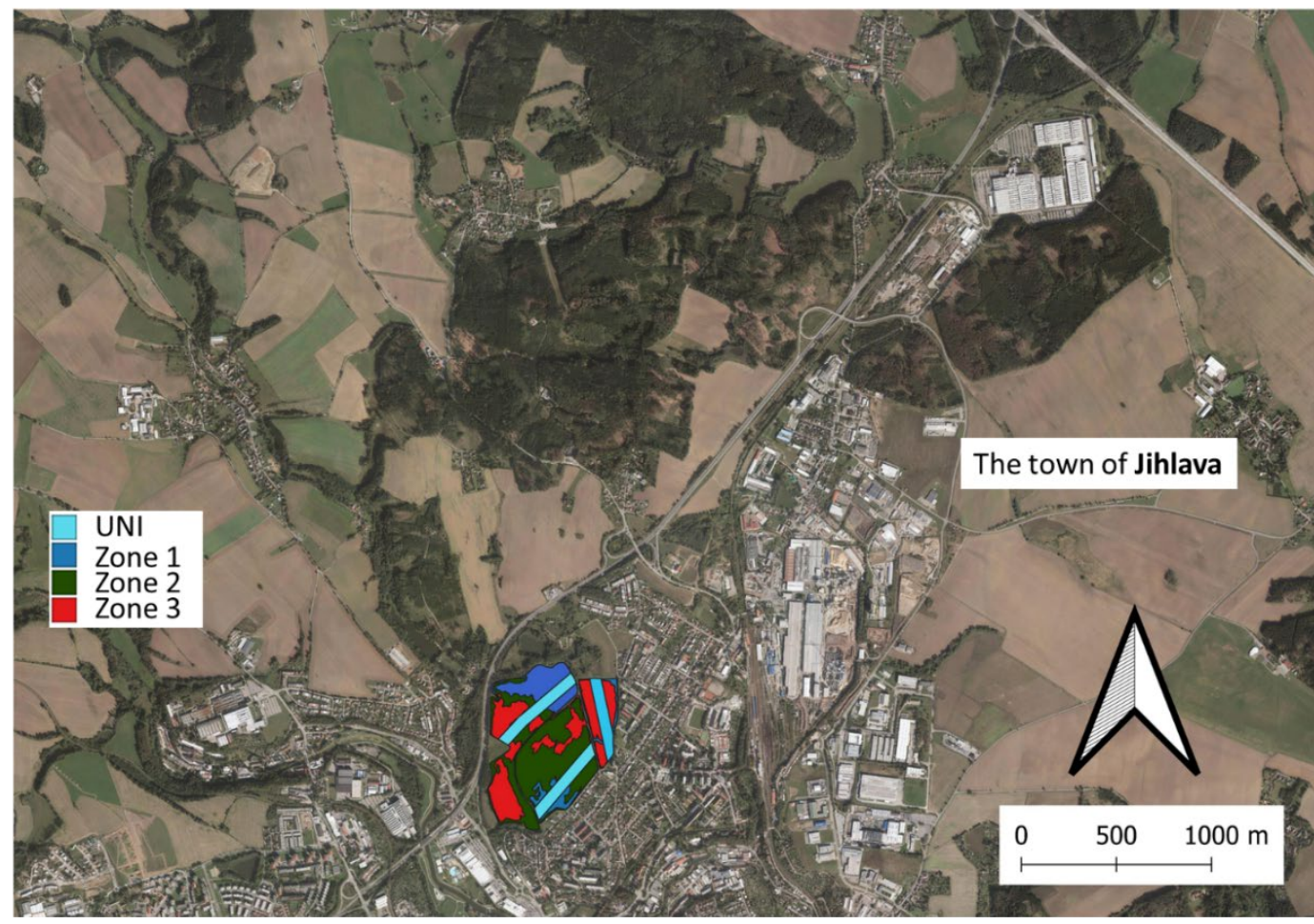

3: Example of an application map with the control strips - field experiment organization in 2019

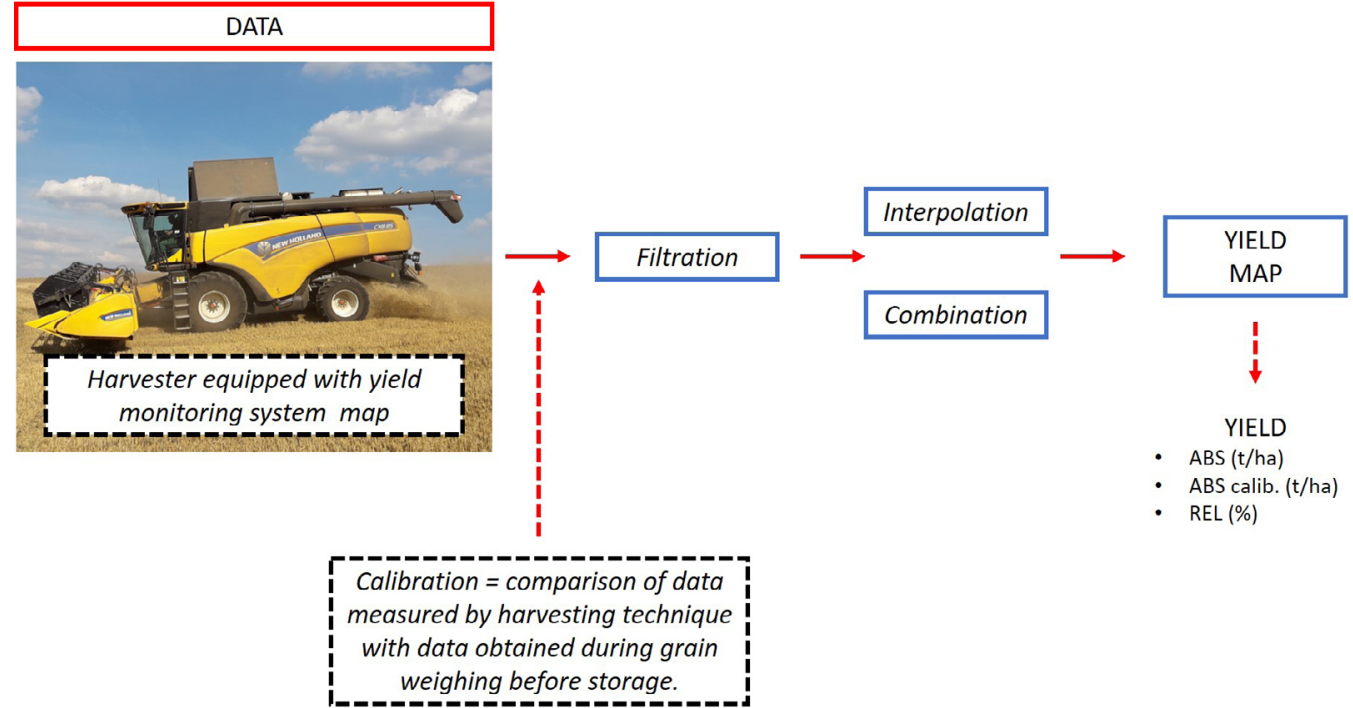

4: Procedure of processing yield data measured by the combine yield monitoring system

experimental fields were directly downloaded from the onboard terminal (IntelliView IV) and processed using the ArcGIS geographic software (ESRI, Redlands, California, USA) and the Pyhton programming language (Python Software Foundation, Wilmington, Delaware, USA). The main aim of data processing was to remove error data at first and then to recalibrate them using the information about the harvested grain weight. Total yield (weight of harvested grain) from each field was determined on the basis of grain weight from the individual fields that was measured before the grain storage.
For this reason, the above characterized method of data processing was developed, which allows the automatic evaluation and recalibration of measured yield data. A simplified scheme of yield data processing is shown in Fig. 4. In detail, the processing of yield data can be divided into the following steps implemented within the experiment:

1) Adjustment of harvest technology terminal.

2) Direct downloading of data from the harvest technology terminal $\rightarrow$ beginning of digital data processing. 
3) Elimination of error data obtained at entering/ leaving the stand.

4) Elimination of error data obtained inside the stand or during the harvest.

5) Elimination of error data obtained due to the wrong bar engagement setting.

6) Different types of yield sensors $\rightarrow$ measurement by means of optics or board.

7) Statistics $\rightarrow$ identification of remote values, minimal and maximal (biological) yield of the plant.

8) Correction/modification of measured yield values between different combine harvesters on the plot $\rightarrow$ finding a function between the two combine harvesters with the yield data.

9) Correction of the values of weight yields.

10) Variants of yield data smoothing.

11) Interpolation of raster yield data.

12) Export in the resulting point and raster data in both absolute and relative terms.

The main output of this process is a yield map with the information about yield in $\%$ or $\mathrm{t} / \mathrm{ha}$. The calculated yield map was used to determine yield differences between the partial plots which were fertilized using the VRA technology and the control strip (control variant - Fig. 4.) where the conventional technology was used. Moreover, the yield map can also be used in the future to calculate more accurately the distribution of $\mathrm{N}$ nutrition in the process of application map preparation. The control strip was an indispensable part of application maps for each experimental field.

\section{Data Treatment}

The measured data were processed using the MS Office Excell 2016 programme (Microsoft, Redmond, Washington, USA) and subsequently evaluated in the Czech version of Statistica 12 software (Dell Software, Round Rock, Texas, USA). The measured values were tested using the analysis of variance (one-way ANOVA; $P<0.05$ ). The assumptions for a valid application of the ANOVA analysis for testing the difference of multiple mean values were confirmed on the basis of Shapiro-Wilk test. Potential differences in measured parameters were analysed and identified using the post-hoc Fischer LSD test. All analyses were performed at a significance level of $P<0.05$.

\section{RESULTS}

The effect of the used NF application technology on the grain yield in 2018 and 2019 is shown in Fig. 6. Yield values are expressed as average values from the respective variably fertilized partial plots (Tab. II) and from the control strips. The yield values were further processed as total weighted means for 2018 and 2019 with the surface area of individual zones of variably fertilized experimental plots in the given year being used as weight (Tab. II).

The measured values show (Fig. 5) that the largest differences between the variants were found in 2018. Yield values ranged from 8.5 to $9.01 \mathrm{t} / \mathrm{ha}$ with the values of standard deviation $( \pm S D)$ not indicating a significant difference in the variance of measured values. The highest yield value (9.01 t/ha) was found in Zone 2 which exhibited a medium

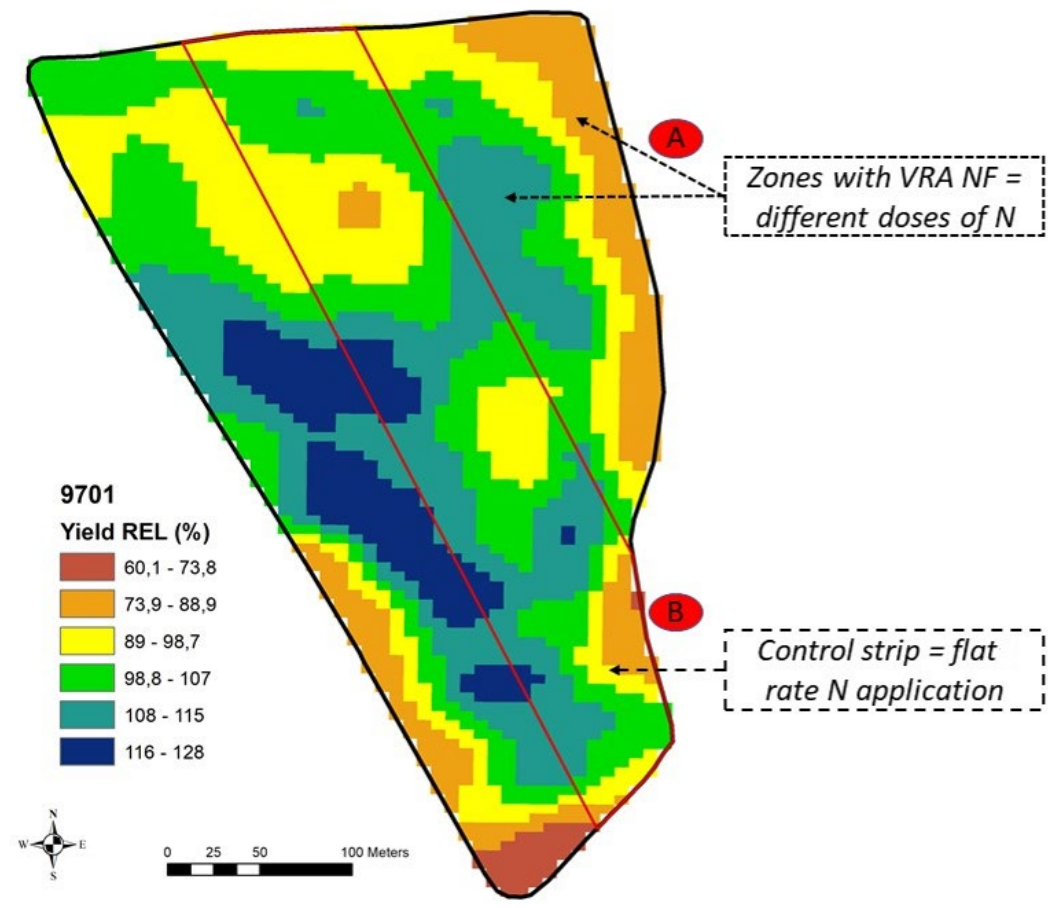

5: Yield and its distribution on Experimental plot no. 9701 in 2019 
yield potential according to the spectral analysis of satellite images. The yield was demonstrably higher as compared with Zone 1 and the control strip (UNI). On the other hand, Zone 3 exhibited a yield similar to that in Zone 2, and no significant difference between the two zones was observed. The generally lowest yield was found in the variant with the uniform $\mathrm{N}$ application. Furthermore, a weighted average of yield was calculated from all zones with VRA N (Tab. II and Tab. III) and compared with the weighted average from the control strips. Weight used in the calculation of weighted average was acreage of individual variants. The weighted average of yield in 2018 reached $8.98 \mathrm{t} / \mathrm{ha}$, which was by $5.39 \%$ more than the weighted average of yield from the control strips (UNI variant), which reached $8.52 \mathrm{t} / \mathrm{ha}$. The difference was statistically significant.

In the second year of the experiment (2019), data were more variable, which was indicated by SD values detected by the analysis of variance. Comparing yields from the variant with the flat rate of $\mathrm{N}$ fertilizer (UNI) and from the VRA NF zones, we found out that they were identical, ranging from 6.7 to $6.85 \mathrm{t} / \mathrm{ha}$. The highest yield was recorded in Zone 1, and the other yields were decreasing in the following order: Zone 1 > UNI > Zone 3 > Zone 2 .
Between the mentioned experimental variants, only a partial statistically significant difference was found between Zone 1 and Zone 2. The other values did not exhibit significant differences. In 2019, weighted averages of yield from all VRA NF zones (Tab. III) were compared with weighted averages from the control strips, too. No significant difference between the respective variants was recorded. Values of both variants were similar, and the difference was negligible, reaching merely 1.9\% in favour of UNI variant.

Significant differences $(\mathrm{P}<0.05)$ were found between the two years of the experiment. In 2018, higher yields were reached in all experimental variants compared with 2019. The fact is confirmed not only by values in the diagram (Fig. 6), but also by weighted averages of yield (Tab. III) showing an apparent decrease between the two years by about more than $20 \%$ across the variants.

\section{DISCUSSION}

In the last two years of the operational experiment described in the presented paper, no negative influence of VRA NF on the yield was observed. Conversely, the measured total grain yields

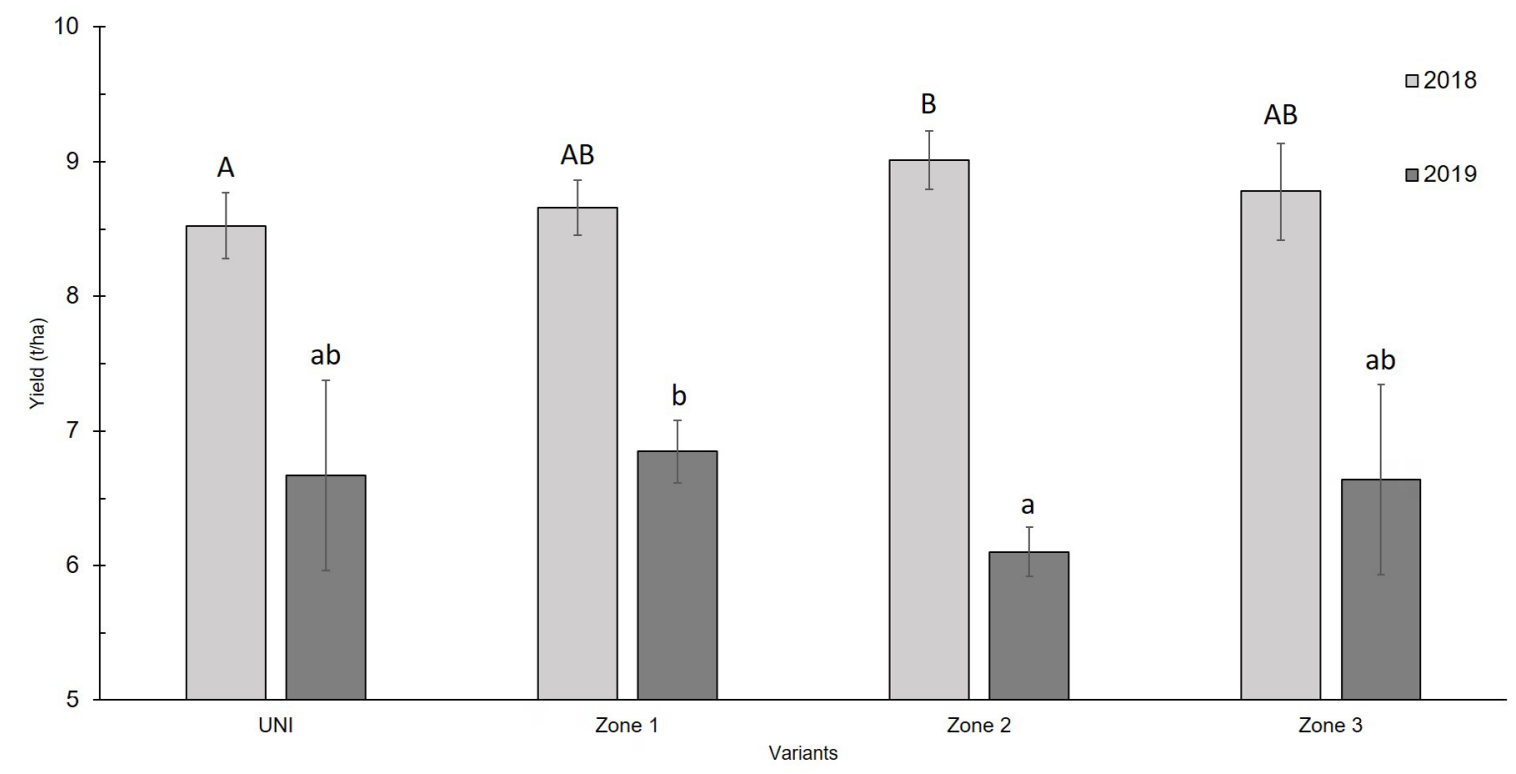

6: Average yields in 2018 and $2019(n=3 ; \pm$ SD) in individual treatments of the field experiment. Different uppercase and small letters show differences between the individual variants in 2018 and 2019, respectively.

III: Average yields from all VRA NF zones and control strips in 2018 and 2019

\begin{tabular}{lcccccc}
\hline \multirow{2}{*}{ Treatment } & \multicolumn{3}{c}{ Yield 2018 } & \multicolumn{3}{c}{ Yield 2019 } \\
\cline { 2 - 7 } & $\begin{array}{c}\text { Average } \\
\text { (t/ha) }\end{array}$ & $\pm \mathrm{SD}$ & $\begin{array}{c}\text { Difference } \\
\text { (rel. \%) }\end{array}$ & Average & \pm SD & $\begin{array}{c}\text { Difference } \\
\text { (rel. \%) }\end{array}$ \\
\hline UNI & 8.52 & 0.24 & $6.39 *$ & 6.67 & 0.71 & 1.98 \\
\hline VRA & 8.98 & 0.38 & & 6.54 & 0.44 & 1.98 \\
\hline
\end{tabular}

Comment on Tab. III: average yields ( $\mathrm{n}=3 \pm \mathrm{SD}$ ) are presented. Symbol $*$ shows significant differences between the UNI and VRA variants in 2018 or 2019. 
confirmed significantly that the VRA N technology had a positive effect on the yield increase in 2018 . The data confirmed that using VRA $\mathrm{N}$ has a potential to promote plant growth because $\mathrm{N}$ is applied on the part of field with the potential for its use and the applied N can be taken up by plants (RodriguezMoreno \& Cid, 2012). This leads to the increased potential of plants to use $\mathrm{N}$ more efficiently than with the flat rate application (Charf et al., 2005). The difference found between the UNI and VRA variants in 2018 was $460 \mathrm{~kg} / \mathrm{ha}$ with the value being very close to those measured in another part of SIL CZ (Elbl et al., 2018), where a benefit ranging from 230 to $317 \mathrm{~kg} / \mathrm{ha}$ was recorded during two years of monitoring with using the same VRA $\mathrm{N}$ technology. For VRA N, we used a so-called yield principle, i.e. a higher NF dose was applied on partial plots with the higher YP and vice versa. We worked with an assumption that plants exhibiting a higher YP would also have a greater capacity of binding and utilizing nitrogen, which was confirmed in 2018. The example of the chosen experimental site (Fig. 5) clearly shows that the yield was decreasing in the most unfavourable partial plots (Zone 1), where machines and vehicles were entering the site or turning. These partial plots exhibit lower fertility over a long term due to soil compaction or impaired capacity of infiltration (Shah et al., 2017). This is why it is not necessary to increase the NF dose because the plants have no potential of using it anyhow. Basso et al. (2016) and Li et al. (2016) who observed that VRA $\mathrm{N}$ reduced the leaching of $\mathrm{N}_{\text {min }}$ from the soil, improved the availability of nitrogen to plants as well as the grain yield arrived at similar conclusions.

Nevertheless, in the following year of the experiment (2019), no demonstrable differences in grain yield were found between the chosen technologies of $\mathrm{N}$ application (UNI vs. VRA). Yield changes (and hence in VRA $\mathrm{N}$ profitability in growing wheat) were found also by Boyer et al. (2011). In their study, the authors stated that VRA N has a potential for increasing the wheat yield but namely when more variable $\mathrm{N}$ doses are applied and the yield is not affected by other factors such as inaccuracy of the used VRA technology or high temporal and spatial stand variability. In the presented paper, the used technology was spectral analysis of satellite stand images made by Sentinel 2 and SPOT satellites, the output of which was NDVI. According to Silleos et al. (2006), Huerta et al. (2013) and Zheng et al. (2018), this procedure is employable for indirect assessment of stand condition. Vizzari et al. (2019) point out a problem that may occur if NDVI is not completed or confronted with other information (soil type, yields in previous years etc.) because recommendations for VRA $\mathrm{N}$ may be distorted. Another risk seen by the authors (Vizzari et al., 2019) is the use of simple linear models where mean rate is equal to standard rate. This may lead to the application of wrong $\mathrm{N}$ dose and hence to the impairment of potential yield of the stand and its quality. This situation was prevented by establishing an optimum $\mathrm{N}$ dose based on Eq. 1, which was at all times determined prior to the regeneration N1 dose in 2018 and 2019. The NDVI index was used only for scheduling the $\mathrm{N}$ dose. Therefore, an assumption exists that the decrease in yield difference was caused by another factor.

In addition to the reduced difference between the respective variants, a significant year-on-year decrease in yield was recorded in 2019 in spite of the fact that the wheat variety was grown again for the purpose of fodder production, i.e. variety with the same potential for $\mathrm{N}$ uptake and utilization. The authors met this situation already

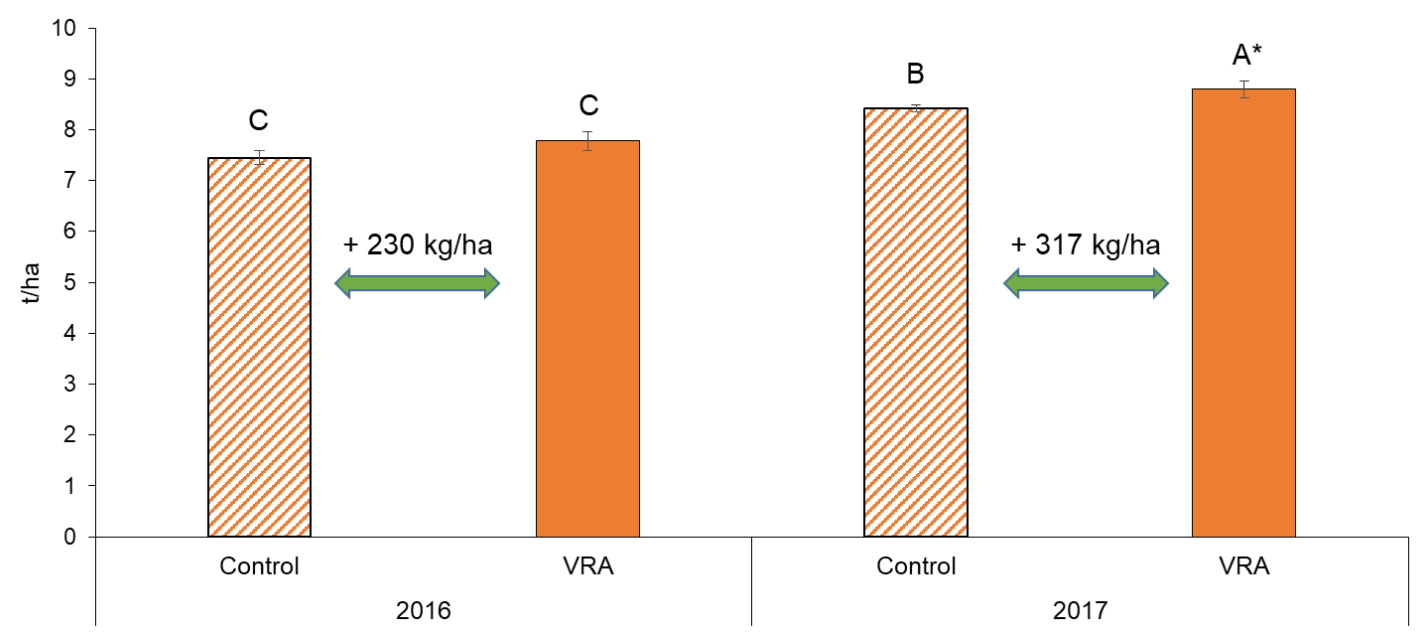

7: Effect of VRA NF on winter wheat grain yield (Elbl et al., 2018)

Comment according to Elbl et al. (2018): Different letters indicate significant differences between the respective variants $(n=3, \pm$ SD; ANOVA, post-hoc Fischer LSD test at $\mathrm{P}<0.05)$ in grain yield in both years of the experiment (2016 and 2017). Symbol * shows significant differences in grain yield between the respective variants in one year. 
in earlier experiments with VRA (Elbl et al., 2018) in another organizational unit of SIL CZ company (Fig. 7). Although the influence of VRA $\mathrm{N}$ on the yield of grain can be favourable, conditions have to be optimal and risk factors have to be eliminated, which follows out for example from the research published by Boyer et al. (2011) or Vizzari et al. (2019). If the plant is stressed e.g. by drought or pest, the $\mathrm{N}$ nutrition or other partial measures in the stand are only of secondary importance for grain yield (Arzanesh et al., 2010; Kintl et al., 2016; He and Dijkstra, 2020). Another problem may be the lack of essential nutrients (P, K, Mg, Ca), which may eliminate the uptake of other nutrients required for plant growth (Shiwakoti et al., 2019). However, such problem was not detected on the sites because the average content of available P (Mehlich III) reached $111 \mathrm{mg} / \mathrm{kg}, \mathrm{K} 171 \mathrm{mg} / \mathrm{kg}$ and $\mathrm{Mg} 176 \mathrm{mg} / \mathrm{kg}$. According to the Czech Central Institute for Supervising and Testing in Agriculture (UKZUZ, 2016), the values represent a good supply of essential nutrients in the given conditions (medium heavy sandy loam). The effect of drought was found though. Total precipitation amounts during the peak of the vegetation season (April-June) significantly differed in the respective years (Tab. I). Thus, the precipitation deficit in 2019 (drop by more than
$85 \mathrm{~mm}$ in the studied period) was apparently the main factor which not only affected the difference in yield in the respective years, more precisely its decrease, but consequently, it probably eliminated the influence of VRA NF on the yield, too. Therefore, it is possible to state that yield in the studied year was affected by drought which eliminated the potential influence of VRA N.

Basso et al. (2011) claim that the yield of wheat is variable in dependence on soil properties, variability of landscape, climate and weather. Contemporary VRA $\mathrm{N}$ technologies in wheat can reflect the current condition of stand (Basso et al., 2011) but cannot work with the potential development of the stand so far such as prediction of stress by drought if occurring outside the scheduled N application (Mulla, 2012; Heege et al., 2013). That would be possible with more complex models for the preparation of application maps or with plots divided into different application zones (Basso et al., 2011; Basso et al., 2016). However, such models are not commonly available to farmers. In any case, their use and hence the replacement of simple models will be necessary for the development of VRA technologies and their long-term profitability (Heege, 2013; Vizzari et al., 2019).

\section{CONCLUSION}

The presented paper describes the potential impact of VRA N on yield and presents results of the field experiment which was not conducted as a conventional field experiment. The effect of VRA N was monitored on an area sized over 60 ha on 6 fields. Each experimental field had a control strip with the flat rate $\mathrm{N}$ application. Furthermore, field measurement was always based on real field (operating) conditions and the used agricultural technologies were at all times conventional (sprayers and spreaders) and typical in the Czech Republic. Therefore, the measured values must be interpreted as results not obtained from small plot experiments, which are usually arrayed in blocks (for example $10 \mathrm{~m} \times 10 \mathrm{~m}$ ). The measured values do not indicate any negative influence of VRA technology on the yield of grain. It is necessary to point out that the expected benefit, i.e. yield increase by min 3\% was recorded only in 2018. In the following year, the difference between the conventional $\mathrm{N}$ application and VRA N technology was minimal. However, the situation is likely to have been caused by drought which adversely affected all stands and corresponding measures were impossible within the applied technology. In the future, the preparation of application maps according to which $\mathrm{N}$ is applied into the winter wheat stand will have to be modified. The application maps should reflect:

a) data from vegetation indices characterizing the current situation on the plot;

b) potential fertility of the plot according to yield potential data;

c) historical fertility according to yield maps for the preceding period of at least 3 years.

Furthermore, it was confirmed within the experiment that if the application maps are properly prepared, i.e. control strips or zones are included, the field experiment can be evaluated with using data from yield meters of combine harvesters. The control belts can thus be used not only for testing the effect of the variable application of fertilizers, but also for testing, e.g. a variable application of pesticides. When the control strip contains a standard or 0 dose and the surrounding parts of the plot are treated variably. However, here we have to point out that the control strip has to run through the entire plot and through the zones of different potential fertility at the best.

\section{Acknowledgements}

This study was supported by Internal Grant Agency of the Faculty of AgriSciences at Mendel University in Brno as the research project AF-IGA2019-IP017 - Evaluation of variable rate application 
of nitrogen fertilizers in precision agriculture and AF-IGA2020-IP054 - Use of satellite systems Landsat and Sentinel-2 for variable rate application of fertilizers. The research was carried out in collaboration with Spearhead Czech Ltd.

\section{REFERENCES}

ARANGUREN, M., CASTELLÓN, A. and AIZPURUA, A. 2019. Crop sensor-based in-season nitrogen management of wheat with manure application. Remote sensing, 11(9): 1094.

ARZANESH, M. H., ALIKHANI, H. A., KHAVAZI, K., RAHIMIAN, H. A. and MIRANSARI, M. 2011. Wheat (Triticum aest ivum L.) growth enhancement by Azospirillum sp. under drought stress. World Journal of Microbiology I, 27: 197-205.

BASSO, B., DUMONT, B., CAMMARANO, D., PEZZUOLO, A., MARINELlO, F. and SARTORI, L. 2016. Environmental and economic benefits of variable rate nitrogen fertilization in a nitrate vulnerable zone. Science of The Total Environment, 545-546: 227-235.

BASSO, B., RITCHIE, J. T., CAMMARANO, D. and SARTORI, L. 2011. A strategic and tactical management approach to select optimal $\mathrm{N}$ fertilizer rates for wheat in a spatially variable field. Eur. J. Agron., 35: 215-222.

BLACKMORE, S., GODWIN, R. J. and FOUNTAS, S. 2003. The Analysis of Spatial and Temporal Trends in Yield Map Data over Six Years. Biosystems Engineering, 84(4): 455-466.

BOYER, N. C., BRORSEN, B. W., SOLIE, J. B. and RAUN, W. R. 2011. Profitability of variable rate nitrogen application in wheat production. Precision Agriculture, 12(4): 473-487.

DELEGIDO, J., VERRELST, J., ALONSO, L. and MORENO, J. 2011. Evaluation of Sentinel-2 red-edge bands for empirical estimation of green LAI and chlorophyll content. Senzors, 11(7): 7063-7081.

DIACONO, M., RUBINO, P. and MONTEMURRO, F. 2013. Precision nitrogen management of wheat, A review. Agronomy for Sustainable Development, 33: 219-241.

ELBL, J., LUKAS, V., KINTL, A., KYNICKÝ, J. and BRTNICKÝ, M. 2018. Variable - rate nitrogen application in wheat production on the basis of satellite images analysis to increase yield and reduce environmental risks. In: $18^{\text {th }}$ International Multidisciplinary Scientific GeoConference SGEM 2018. Sofie: STEF92 Technology, pp. 725-732.

HANDLÍŘOVÁ, M., LUKAS, V. and SMUTNÝ, V. 2017. Yield and soil coverage of catch crops and their impact on the yield of spring barley. Plant, Soil and Environment, 63(5): 195-200.

HANSEN, P. M. and SCHJOERRING, J. K. 2003. Reflectance measurement of canopy biomass and nitrogen status in wheat crops using normalized difference vegetation indices and partial least squares regression. Remote Sensing of Environment, 86(4): 542-553.

HE, M. and DIJKSTRA, F. A. 2020. Drought effect on plant nitrogen and phosphorus: a meta-analysis. New Phytologist, 204(4): 924-931.

HEEGE, H. J. (Ed.). 2013. Precision in Crop Farming. Dordrecht: Springer Netherlands.

HEEGE, H. J., REUSCH, S. and THIESSEN, E. 2008. Prospects and results for optical systems for sitespecific on-the-go control of nitrogen-top-dressing in Germany. Precision Agriculture, 9(3): 115-131.

HLAVINKA, P., TRNKA, M., KERSEBAUM, K. C., ČERMÁK, P., POHANKOVÁ, E., ORSÁG, M., POKORNÝ, E., FISCHER, M., BRTNICKÝ, M. and ŽALUD, Z. 2013. Modelling of yields and soil nitrogen dynamics for crop rotations by HERMES under different climate and soil conditions in the Czech Republic. Journal of Agricultural Science, 152(2): 188-204.

KINTL, A., NAWRATH, A., ELBL, J., TƯMA, I., MUCHOVÁ, M., BRTNICKÝ M. and KYNICKÝ, J. 2016. Nitrogen and phosphorus availability effect on activity of cellulotyc microorganisms in meadows. Acta Univ. Agric. Silvic. Mendelianea Brun., 64(4): 1173-1179.

KLEM, K., HŘIVNA, L., RYANT, P. and MÍŠA, P. 2011. Využití diagnostických metod pro rozhodovací procesy $v$ pěstební technologii jarního ječmene - Use of diagnostic methods for decide processes in spring barley growing technology. Brno: Mendel University in Brno.

LAL, R. 2018. Soil Nitrogen Uses and Environmental Impacts. Series: Advances in soil science. Boca Raton, FL: CRC Press, Taylor \& Francis Group.

LI, A., DUVAL, B. D., ANEX, R., SCHARF, P., ASHTEKAR, J. M., OWENS, P. R. and ELLIS, C. 2016. A Case Study of Environmental Benefits of Sensor-Based Nitrogen Application in Corn. Journal of Environmental Quality, 5(2): 675-683.

LOŠÁK, T., HLUŠEK, J., ZATLOUKALOVÁ, A., MUSILOVÁ, L., VÍTĚZOVÁ, M., ŠKARPA, P., ZLÁMALOVÁ, T., FRYČ, J., VÍTĚZ, T. and MAREČEK, J. 2014. Digestate from biogas plants is an attractive alternative to mineral fertilisation of Kohlrabi. Journal of Sustainable Development of Energy, Water and Environment Systems, 2(4): 309-318. 
LUKAS, V., RYANT, P., NEUDERT, L., DRYŠLOVÁ, T., GNIP, P. and SMUTNÝ, V. 2012. Stanovení a optimalizace diferencovaných dávek dusíkatých hnojiv v precizním zemédělství - Determination and optimization of differentiated doses of nitrogenous fertilizers in precision agriculture. Brno: Mendelova univerzita v Brně.

MULLA, D. J. 2012. Twenty five years of remote sensing in precision agriculture: Key advances and remaining knowledge gaps. Biosystems Engineering, 114(4): 358-371.

MUÑOZ-HUERTA, R. F., GUEVARA-GONZALEZ, R. G., CONTRERAS-MEDINA, L. M., TORRES-PACHECO, I., PRADO-OLIVAREZ, J. and OCAMPO-VELAZQUEZ, R. V. 2013. A review of methods for sensing the nitrogen status in plants: advantages, disadvantages and recent advances. Sensors, 13(8): 1082310843.

OROSZ, F., JAKAB, S., LOŠÁK, T. and SLEZAK, K. 2009. Effects of fertilizer application to sweet corn (Zea mays.) grown on sandy soil. Journal of Environmental Biology, 30(6): 933-938.

RODRIGUEZ-MORENO, F. and CID, F. 2012. A decision tree for nitrogen application based on a lowcost radiometry. Precision Agriculture, 13(6): 646-660.

SANTHOSH, K. et al. 2003. Remote sensing applications for precision agriculture: A learning community approach. Remote Sensing of Environment, 88(1-2): 157-169.

SCHARF, P. C., KITCHEN, N. R., SUDDUTH, K. A., DAVIS, J. G., HUBBARD, V. C. and LORY, J. 2005. A. Fieldscale variability in optimal nitrogen fertilizer rate for corn. Agronomy Journal, 97(2): 452-461.

SHAH, A. N., TANVEER, M., SHAHZAD, B. et al. 2017. Soil compaction effects on soil health and cropproductivity: an overview. Environ. Sci. Pollut. Res., 24(11): 10056-10067.

SHANAHAN, J. F., KITCHEN, N. R., RAUN, W. R. and SCHEPERS, J. S. 2008. Responsive in-season nitrogen management for cereals. Computers and Electronics in Agriculture, 61(1): 51-62.

SHIWAKOTI, S., ZHELJAZKOV, V. D., GOLLANY, H. T., KLEBER, M. and XING, B. 2019. Macronutrients in soil and wheat as affected by a long-term tillage and nitrogen fertilization in winter wheatfallow rotation. Agronomy, 9(4): 178.

SILLEOS, N. G., ALEXANDRIDIS, T. K., GITAS, I. Z. and PERAKI, K. 2006. Vegetation indices: advances made in biomass estimation and vegetation monitoring in the last 30 years. Geocarto Int., 21(4): 21-28.

STATSOFT CR. 2021. Statistica (data analysis software). Version 12. Available at: www.statsoft.cz.

SUTTON, M. A. 2011. The European nitrogen assessment: sources, effects and policy perspectives. Cambridge University Press.

UKZUZ. 2016. Methodical instruction no. 9: working procedures for agrochemical testing of agricultural soils in the Czech Republic in the period 2017-2022. Prague: Central Institute for Supervising and Testing in Agriculture.

VIZZARI, M., SANTAGA, F. and BENINCASA, P. 2019. Sentinel 2-based bitrogen VRT fertilization in wheat: comparison between traditional and simple precision practices. Agronomy, 9(6): 278.

WANG, R. F., AN, D. G., HU, C. S., LI, L. H., ZHANG, Y. M., JIA, Y. G. and TONG, Y. P. 2011. Relationship between nitrogen uptake and use efficiency of winter wheat grown in the North China Plain. Crop and Pasture Science, 62(6): 504-514.

ZHANG, X., DAVIDSON, E. A., MAUZERALL, D. L., SEARCHINGER, T. D., DUMAS, P. and SHEN, Y. 2015. Manging nitrogen for sustainable development. Nature, 528(7580): 57-59.

ZHENG, Q., HUANG, W., CUI, X., SHI, Y. and LIU, L. 2018. New Spectral Index for Detecting Wheat Yellow Rust Using Sentinel-2 Multispectral Imagery. Sensors, 18(3): 868.

Contact information

Jakub Elbl: jakub.elbl@mendelu.cz 
